\title{
Você pode ser gorda: questões para os feminismos
}

You Can Be Fat: Questions for Feminisms

\author{
Lysia da Silva Almeida' (iD) 0000-0002-3810-5946 \\ 'Instituto Federal de Educação, Ciência e Tecnologia do Espírito Santo, Programa de \\ Pós-Graduação em Ensino de Humanidades, Vitória, ES, Brasil. 29040-780 - \\ ppgeh.vi@ifes.edu.br
}

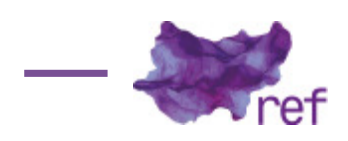

TOVAR, Virgie.

Meu corpo, minhas medidas.

Trad. de Mabi Costa. São Paulo: Primavera Editorial, 2018.

\begin{abstract}
A escritora Virgie Tovar, uma das principais especialistas em discriminação baseada no peso e imagem corporal da atualidade, se apresenta como feminista, palestrante e ativista gorda. Sua luta contra a gordofobia ficou muito conhecida quando criou a campanha \#LoseHateNotWeight ${ }^{1}$, o que condiz com sua linguagem concisa e bem-humorada. Bacharel em Ciência Política, mestra em Estudos da Sexualidade, com ênfase nas interseções entre tamanho corporal, raça e gênero, Tovar começou a escrever livros como parte de sua atuação política.

Lançou nos EUA o livro Hot \& Heavy: Fierce Fat Girls on Life, Love and Fashion ${ }^{2}$, pela editora Seal Press em 2012, e já tem outra obra prevista para 2020 intitulada The Self-Love Revolution: Radical Body Positivity for Girls of Color ${ }^{3}$, pela New Harbinger Publications. O manifesto You Have the Right to Remain Fat ${ }^{4}$, lançado em 2018 pela editora Feminist Press, é a obra de estreia da autora no Brasil. Chegou no mesmo ano pela Primavera Editorial e aqui recebeu o título Meu corpo, minhas medidas. Ainda que o título em português não expresse tanto o caráter de confrontamento ao status quo, a obra está recheada de críticas importantes para a sociedade atual e reflexões fundamentais para a construção dos feminismos contemporâneos.

Ao longo de doze capítulos, há uma mescla entre estudos acadêmicos e registros da experiência pessoal como uma mulher latino-americana e gorda nos Estados Unidos. Por ter passado anos refém de uma cultura que prioriza os corpos encaixados no padrão, Tovar praticava a restrição alimentar buscando modificar o próprio corpo e, por isso, vivia em constante culpa e angústia por comer. Ao ter acesso às discussões do ativismo gordo, sua perspectiva mudou, e o livro é um registro de como a autora compreende a gordofobia: uma opressão estrutural que exige enfrentamento político.
\end{abstract}

Já na introdução, temos algumas histórias de sua infância, juntamente com relatos de transtornos alimentares e exposição de casos de gordofobia médica sofridos por pessoas que ela

' \#PercaÓdioNãoPeso

${ }^{2}$ Quente e pesada: garotas gordas ferozes na vida, no amor e na moda.

${ }^{3}$ A revolução do amor próprio: positividade corporal radical para meninas de cor.

${ }^{4}$ Você tem o direito de permanecer gorda. 
conheceu ao longo dos anos como militante. Tais narrativas são o panorama para a afirmação corajosa e assustadora de que vivemos em uma cultura das dietas, e isso é não apenas uma forma de opressão feminina como também um "feminicídio assistido" (TOVAR, 2018, s. p.). Em um primeiro momento, essa constatação parece chocante, mas ao longo da obra se apresentam elementos que contribuem para confirmar a hipótese.

Em "Gordofobia e cultura da dieta: o que são?", a autora apresenta a definição do problema social que denuncia: uma ideologia que inferioriza pessoas gordas e coloca-as como alvo do ódio, quando se impõe que apenas a magreza é bela e saudável. Esse preconceito se manifesta, entre outras formas, pela linguagem, a qual naturaliza um ideal de beleza e saúde que exclui determinados corpos. Ainda neste capítulo, há uma provocação de que todos somos alvo da gordofobia, porque até quem não é gordo está em constante (auto)controle por medo de se tornar uma pessoa gorda, e esse é o cenário da obsessão pelas dietas, que, no entanto, não está tratado pelo plano individual, mas olhando para a indústria multibilionária que coloca as dietas como inevitáveis.

No capítulo seguinte, "Restrição alimentar não é para você", Tovar continua questionando a lucrativa indústria das dietas, e vai além, aproximando ainda mais sua relação com a gordofobia. Para tanto, traz pesquisas indicando como essa indústria é falha e culpabiliza seus consumidores pelo fracasso, em especial as mulheres, principal público desse ramo. Diante disso, apresenta dados que versam sobre a condição de baixa autoestima das mulheres gordas causadas pela frustração legitimada na cultura do emagrecimento, provocando uma condição de vulnerabilidade que se reflete inclusive no comportamento sexual.

No capítulo "Dieta: família, assimilação e bootstrapping", há uma brilhante associação da cultura norte-americana com as dietas. Tovar explica que bootstrapping é a ideia de que, com determinação e dedicação, pode-se realizar qualquer objetivo, um pilar da mentalidade dos EUA. Relacionar o discurso das dietas com a noção de meritocracia significa entender que não obter êxito em uma dieta é uma questão social e coletiva, e não se limita ao individual nem por falta de esforço. Tovar mostra, ainda, que a categoria "gorda" é uma invenção criada apenas para controlar as pessoas, assim como "gay" e "hétero", e constata que pessoas racializadas são ainda mais cobradas a se adequarem à magreza, uma vez que é uma das exigências da branquitude. A autora afirma, entretanto, que se sentia inferior por ser gorda de forma mais explícita do que em relação às questões de gênero e raça.

As dietas são um processo abusivo e doloroso ao qual submetemos nosso corpo, e por isso "Dieta é uma tática de sobrevivência" é um capítulo mais íntimo, no qual as questões anteriormente debatidas por um viés acadêmico ganham uma carga afetiva. Nele, Tovar tenta evidenciar que o livro não tem a intenção de julgar os indivíduos, mas compreender que a cultura das dietas é um efeito da gordofobia, e isso tem nos colocado, enquanto sociedade, na mira desse mecanismo de controle e de subjetivação.

"Inferioridade interiorizada e sexismo" mostra como o peso é um indício de moralidade e está vinculado à misoginia de muitas formas. A autora sugere que, do mesmo modo que parte das mulheres ainda não está convencida que o sexismo existe e é um problema que as afeta, isso também ocorre com o preconceito corporal. Tovar argumenta que ser uma mulher gorda a coloca numa posição de ter o gênero questionado, por não corresponder ao ideal de feminilidade branco, o qual se expressa numa imagem de docilidade, submissão e pequenez. A exigência de que mulheres sejam sempre bonitas, como se fosse uma obrigação ao gênero feminino, é mais enfatizada em se tratando de mulheres gordas. Além disso, o capítulo traz uma referência astuta ao sugerir que o gaslighting é usado como arma do mercado, porque as dietas fazem as mulheres questionarem suas próprias vontades.

O corpo feminino gordo, em certos contextos, é apresentado como moeda em troca de afetividade. Sobre isso, no capítulo "Os caras < 3 magreza: hetero-masculinidade e raça branca", Tovar discute relações de gênero ao escancarar a participação masculina na manutenção desse sistema de opressão. Aparentemente, ao considerar um aspecto mais privado, a autora não deixa de denunciar o caráter sistêmico da gordofobia; contudo, sem medo, indica a necessidade de rever posturas, especialmente quando ressalta que as mulheres em busca da magreza são agentes da misoginia. Nesse sentido, aponta que todas as mulheres são subjugadas pelo machismo, mas mulheres gordas, além disso, são desumanizadas. Nessa discussão, a autora compara brevemente a gordofobia com questões de raça, enfatizando que a supremacia branca opera na mesma lógica de desumanização.

Em "A gordofobia é a nova linguagem do classismo e do racismo", Tovar analisa a representação de crianças gordas em uma campanha contra a obesidade infantil. Nessas propagandas, a autora percebe a diferença de tratamento direcionada a uma menina negra em comparação com as outras crianças brancas. Ainda que todos os corpos ali estivessem contando histórias sobre a gordura, grupos pobres e racializados estavam marcados por uma responsabilização mais evidente e cruel. Esse capítulo traz ponderações muito interessantes sobre classe, raça, sexualidade e tamanho do corpo. 
O capítulo "O que aprendi nos primórdios do gordativismo", mostra a proximidade de Tovar a grupos queer, e como o contato dos ativistas gordos com a militância das sexualidades e expressões de gênero dissidentes resultou em um senso de luta política, enfrentamento e busca por libertação. Mas, se antes discutia-se nesse meio a ameaça que pessoas gordas simbolizam à heteronormatividade e questionava-se noções de saúde impostas pelo sistema capitalista, a emergência do body positivity trouxe um esvaziamento das pautas, reduzindo-as a uma busca por amor próprio e auto aceitação. Para a autora, o discurso da positividade corporal não tem um propósito articulado e, por não responsabilizar o sistema, não traça estratégias de luta para destruí-lo.

Os últimos capítulos - "Quando sonho com meu futuro, me vejo gorda", "Quero liberdade" e "Você tem o direito de permanecer gorda" - são um convite a disputar outros discursos em contraposição ao discurso hegemônico da cultura das dietas, e conhecer as reinvindicações do ativismo gordo. Ela pondera que "Qualquer futuro que não seja centrado na erradicação da opressão e na liberdade coletiva não é um futuro que valha a pena imaginar" (TOVAR, 2018, s. p.).

O propósito do livro é apresentar a gordofobia como uma forma de controle dos corpos e das vidas dos sujeitos e, para evidenciar essa questão, recorre à cultura das dietas e seu impacto na população em geral. Entendemos, contudo, que o debate poderia ter se estendido mais e discutido com profundidade os elementos que sustentam a hipótese apresentada. Além disso, a obra apresenta algumas insuficiências na tradução, por exemplo quando esta utiliza eufemismos como "gordinha", ação que não condiz com a postura que a autora se coloca, sempre na posição de contestar a linguagem, o discurso médico e setores do capitalismo. Ainda assim, são apresentados conceitos importantes e inovadores para pesquisas sobre o tema, contribuindo para que o debate sobre as questões do corpo e da gordofobia, ainda tão incipientes no Brasil, sejam cada vez mais popularizados, em especial ao pensarmos quais feminismos queremos compor.

\section{Referências}

TOVAR, Virgie. Meu corpo, minhas medidas. Trad. de Mabi Costa. São Paulo: Primavera Editorial, 2018.

Lysia da Silva Almeida (lysiaalmeida@gmail.com) é mestranda do Programa de PósGraduação em Ensino de Humanidades do Instituto Federal de Educação, Ciência e Tecnologia do Espírito Santo. Licenciada em História pela UFES (2016). Atualmente pesquisa na área de Práticas Educativas, sobretudo quando dialogam com os estudos de corpo, gênero e sexualidades.

\section{COMO CITAR ESSE ARTIGO DE ACORDO COM AS NORMAS DA REVISTA}

ALMEIDA, Lysia da Silva. "Você pode ser gorda: questões para os feminismos". Revista Estudos Feministas, Florianópolis, v. 28, n. 2, e67775, 2020.

\section{CONTRIBUIÇÃO DE AUTORIA}

Não se aplica.

\section{FINANCIAMENTO}

Não se aplica.

\section{CONSENTIMENTO DE USO DE IMAGEM}

Não se aplica.

APROVAÇÃO DE COMITÊ DE ÉTICA EM PESQUISA

Não se aplica.

\section{CONFLITO DE INTERESSES}

Não se aplica.

LICENÇA DE USO

Este artigo está licenciado sob a Licença Creative Commons CC-BY International. Com essa licença você pode compartilhar, adaptar, criar para qualquer fim, desde que atribua a autoria da obra. 


\section{HISTÓRICO}

Recebido em 26/09/2019

Aprovado em 13/01/2020 